\title{
How to Measure the Absorption and Desorption Curves of Superabsorbent Polymers in the Presence of Calcium lons
}

\author{
Qing Jiang ${ }^{1}$ and Keshu Wan ${ }^{2 *}$
}

\begin{abstract}
The absorption and desorption curve of superabsorbent polymers (SAP), which reflects key information of the maximum absorbency and retention capacity, is crucial for the mix designs of internally cured concretes. In this paper, the effect of amount of $\mathrm{Ca}^{2+}$ on the absorption and desorption curve of SAP is studied. Results show that the proportion between amount of $\mathrm{Ca}^{2+}$ and SAP mass has a notable influence on the absorption and desorption curve of SAP, whether in tap water or mimicked pore solution of cement paste. Considering the important effect of amount of $\mathrm{Ca}^{2+}$, it is suggested that researchers need to determine the relationship between the retention capacity and the ratio of amount of $\mathrm{Ca}^{2+}$ to SAP mass in advance before formal measurement using classic tea bag method or filtration method. Furthermore, from the view of the ion exchange equilibrium between SAP and $\mathrm{Ca}^{2+}$, we discussed the mechanism that amount of $\mathrm{Ca}^{2+}$, concentration of $\mathrm{Ca}^{2+}$, SAP type, alkalinity, etc. have decisive effect on the absorption and desorption curve.
\end{abstract}

\section{Introduction}

Superabsorbent polymers (SAP), which are widely used in sanitation industry, have been suggested as an internal curing agent for low water-cement ratio concrete in the past two decades. A large number of studies (Jensen et al. 2001, 2002, 2006; Snoeck et al. 2015; Bentz et al. 2004; Justs et al. 2015) have shown that SAP can maintain high humidity inside internally cured concretes and significantly reduce the early-age shrinkage of the concretes. Besides, the applications of SAP in rheology control, frost protection (Kang et al. 2015; Monnig et al. 2007; Laustsen et al. 2015) and crack sealing (Tsuji et al. 1998, 1999; Lee et al. 2010; Snoeck et al. 2012) can be found in concrete field.

The absorption and desorption curve of SAP, namely swelling and de-swelling behavior of SAP, containing crucial information of maximum absorbency and retention capacity, plays a critical role in the mix design of internally cured concretes. Therefore, it is important to measure the curve precisely. Different measuring methods have been developed. According to the measuring environments, existing methods can be roughly divided into two categories. One is to measure the absorption and desorption curve of SAP in cement pastes. The other is to measure the curve in liquids.

For the measurement in cement pastes, Yang et al.

\footnotetext{
${ }^{1}$ Graduate student, School of Materials Science and Engineering, Southeast University, Nanjing, 211189, People's Republic of China.

${ }^{2}$ Professor, Jiangsu Key Laboratory of Construction Materials, School of Materials Science and Engineering, Southeast University, Nanjing, 211189, People's Republic of China. *Corresponding author,

E-mail: keshuwan@seu.edu.cn
}

(2019) took out SAP embedded in cement pastes to measure the absorption and desorption curves by weighing method before setting. Snoeck et al. (2014) compared the slump of cement pastes mixed with different amounts of SAP, and derived amount of water absorbed in the process of mixing according to the slump difference. Schrofl et al. (2015) deduced relative water changes of SAP by comparing neutron radiography images at different times. Snoeck et al. (2017) use Nuclear Magnetic Resonance (NMR) to determine migrating amounts of water from SAP into the surrounding matrix. Although these methods can measure the curve in real cement pastes, the weaknesses are apparent. The former two methods can only reflect the absorption and desorption curve before setting and are not sufficiently accurate for real absorbency. The latter two methods require advanced imaging techniques, resulting in low practical values.

Compared with the measuring methods in cement pastes, the measuring methods in liquids are relatively simple, such as the tea bag method, the filtration method, image analysis method and the laser diffraction method (Esteves 2015; Davis et al. 2018). Among these methods, the tea bag method (Kang et al. 2017, 2018; Schrofl et al. 2012, 2015; Snoeck et al. 2017; Zhao et al. 2020) and the filtration method (Snoeck et al. 2012; Lee et al. 1996) are widely adopted.

For classic tea bag method and filtration method, researchers have made many efforts to improve the measurement accuracy, such as removing the water between particles by centrifugation and selecting appropriate ion and ions concentration in mimicked pore solutions. For suitable mimicked pore solution, $\mathrm{Ca}^{2+}$, which has a striking effect on the absorption and desorption curves of SAP, is indispensable. In 1990, researchers in the soil field have found that divalent and trivalent cations such as $\mathrm{Ca}^{2+}$ had a fatal effect on the retention capacity of 
Table 1 The SAP used in this study.

\begin{tabular}{cccc}
\hline Name & Corporation & Particle size $(\mu \mathrm{m})$ & Color \\
\hline SAP-A-150-W & Wanhua & $100-200$ & White \\
SAP-A-850-W & Wanhua & $800-900$ & White \\
SAP-B-150-W & Shenyang corestone & $100-200$ & White \\
SAP-B-850-W & Shenyang corestone & $800-900$ & White \\
SAP-B-2150-R & Shenyang corestone & $2000-2300$ & Red \\
\hline
\end{tabular}

SAP (Bowman et al. 1990), which was also reported by the researchers of resin industry (Jar et al. 1997; Siriwatwechakul et al. 2012; Yarimkaya et al. 2007). Of course, the presence of $\mathrm{Ca}^{2+}$ in liquid has also a positive application. For example, researcher reported that the additional of $\mathrm{Ca}^{2+}$ helps to depress the initial swelling of SAP to reduce its impact on strength so that a higher SAP dosage can be used to enhance crack sealing (Lee et al. 2016). As for underlying mechanism, it is generally believed that each $\mathrm{Ca}^{2+}$ entering SAP binds two carboxyl groups, which is equivalent to the ion cross-linking effect (see Fig. 1), resulting in the increased degree of cross-linking inside SAP (Jar et al. 1997; Lee et al. 2018). Consequently, SAP will release water. .

By applying classic tea bag method, in the field of internal curing, some experimental studies (Yang et al. 2019; Schrofl et al. 2012, 2015; Kang et al. 2017, 2018; Zhu et al. 2015; Lee et al. 2018) have also reported that the retention capacity of SAP became worse in solutions containing $\mathrm{Ca}^{2+}$. In addition, other crucial factors, such as the alkalinity of solutions and chemical composition of SAP, imposed on interaction between SAP and $\mathrm{Ca}^{2+}$ were also reported. Lee et al. (2018) found both the alkalinity and the concentration of $\mathrm{Ca}^{2+}$ (COC) in pore solution had the critical effects on the absorption and desorption curve of SAP. Schrofl et al. (2012) found that SAP with different molecular structure exerted dramatically distinct effects on the absorption and desorption curve of SAP in solution containing $\mathrm{Ca}^{2+}$. Kang et al. (2018) have even concluded that higher $\mathrm{Na}^{+}, \mathrm{K}^{+}$ concentration in pore solution lowered initial absorbency and amount of $\mathrm{Ca}^{2+}$ inside SAP, as a consequence improving the water retention capacity of SAP.

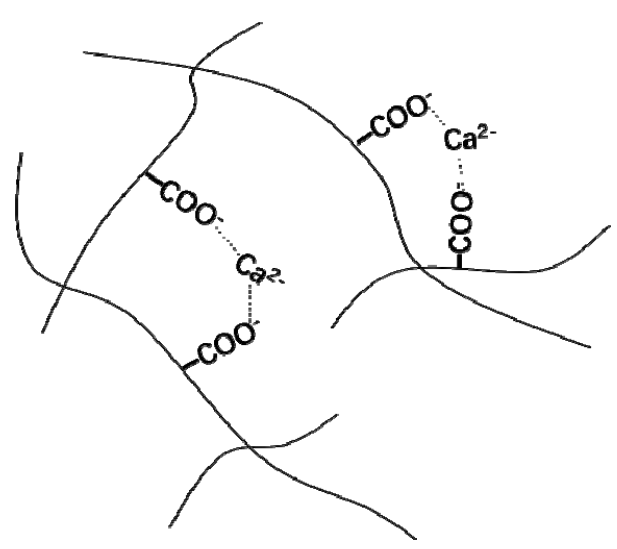

Fig. 1 Schematic illustrating ionic crosslink formation with $\mathrm{Ca}^{2+}$ which hinders swelling.
Overall, based on the tea bag method or the filtration method, some researchers have studied the effect of SAP type, alkalinity and COC of pore solution on the absorption and desorption curve of SAP. In this study, we found that the ratio between amount of $\mathrm{Ca}^{2+}$ (AOC) and SAP mass have a decisive effect on the absorption and desorption curve of SAP. If researchers do not eliminate the $\mathrm{Ca}^{2+}$ induced uncertainty of the measured curves, it is possible to wrongly measure the absorption and desorption curves of SAP in the internal curing field. Why do AOC, COC, SAP type, alkalinity, etc. have decisive effect on the curve? We discussed the mechanism from the view of ion exchange equilibrium in this study.

\section{Experimental}

\subsection{Applied SAP}

SAP commonly used in concretes can be mainly divided into two types, namely (poly)acrylic acid type (poly(AA)) and (poly)acrylic acid-co-acrylamide type (poly(AM)). Only poly(AA)-type SAP was used in this study for following reasons. Compared to poly(AM)-type SAP, poly(AA)-type SAP has much higher absorbency, is prone to be influenced by calcium ion; and is available for purchase in China market. To compare the absorption and desorption behaviors of more poly(AA)-type SAPs, SAPs from two different corporations were applied. They are respectively labeled SAP A (Wanhua, China) and SAP B (Shenyang Cornerstone, China). The particle size distribution of SAP A and SAP B is divided into two categories (100-200 $\mu \mathrm{m}$ and $800-900 \mu \mathrm{m})$ in all experiments. Further, in order to observe the outline of SAP in liquids intuitively through optical microscope (Supereye, B007 digital optical microscope), red SAP B with particle size of 2-2.3 mm (dyed with organic dyes) was used to take photographs. The purpose of photographing is just to distinguish between the large size differences of SAP using naked eye. The absorption and desorption curves were obtained through weighing method. In order to easily distinguish the SAP used, SAP from different companies, with different colors and particle sizes are named in Table 1.

\subsection{Prepared liquids}

Five kinds of liquids were prepared and specific details are shown in Table 2. S0 is deionized water, COC of which can be regard as $0 \mathrm{mM}$. S1 is tap water, containing very low concentration of multivalent ion $(0.5$ mM-1.5 mM) according to GB5749-2006 of China. S2 and S3 with same total ion concentration were prepared 
Table 2 The liquids used in this study.

\begin{tabular}{|c|c|c|c|c|c|}
\hline \multirow{2}{*}{ Solution } & \multicolumn{3}{|c|}{ Cations concentration (mM) } & \multirow{2}{*}{$\mathrm{pH}$} & \multirow{2}{*}{$\begin{array}{l}\text { Total ions concentration } \\
(\mathrm{mM})\end{array}$} \\
\hline & $\mathrm{Na}^{+}$ & $\mathrm{K}^{+}$ & $\mathrm{Ca}^{2+}$ & & \\
\hline S0 (Deionized water) & 0.00 & 0.00 & 0.00 & 7.00 & 0.00 \\
\hline S1 (Tap water) & l & l & $0.50-1.00$ & 6.88 & I \\
\hline $\mathrm{S} 2$ & 20.25 & 52.55 & 22.30 & 6.98 & 212.50 \\
\hline S3 & 20.25 & 81.02 & 3.32 & 6.82 & 212.50 \\
\hline S4 & 20.25 & 52.55 & 22.30 & 12.42 & 212.50 \\
\hline
\end{tabular}

Table 3 Experimental design of 16 experiments, where $\mathrm{M}_{\mathrm{SAP}}$ and $\mathrm{V}_{\text {solution }}$ represent mass of SAP and volume of solution, $\mathrm{COC}$ and $\mathrm{AOC}$ are the concentration and amount of $\mathrm{Ca}^{2+}$, respectively, and $\mathrm{N}$ is the ratio between $\mathrm{AOC}$ and $\mathrm{M}$ SAP. In group E0-E3, SAP-B-2150-R was used to take photographs.

\begin{tabular}{|c|c|c|c|c|c|c|c|}
\hline Group & $\mathrm{M}_{\mathrm{SAP}}(\mathrm{g})$ & $\mathrm{V}_{\text {solution }}(\mathrm{ml})$ & SAP Name & Solution & $\begin{array}{l}\text { COC } \\
(\mathrm{mM})\end{array}$ & $\mathrm{AOC}(\mathrm{mmol})$ & $\begin{array}{c}\mathrm{N} \\
(\mathrm{mmol} / \mathrm{g})\end{array}$ \\
\hline E0 & 0.008 & 150.000 & SAP-B-2150-R & S0 & 0.000 & 0.000 & 0.000 \\
\hline E1 & 0.680 & 150.000 & SAP-B-2150-R & So & 0.000 & 0.000 & 0.000 \\
\hline $\mathrm{E} 2$ & 0.008 & 150.000 & SAP-B-2150-R & $\mathrm{S} 1$ & $0.500-1.000$ & $0.070-0.150$ & $9.380-18.750$ \\
\hline E3 & 0.680 & 150.000 & SAP-B-2150-R & $\mathrm{S} 1$ & $0.500-1.000$ & $0.070-0.150$ & $0.150-0.290$ \\
\hline E4 & 0.1 & 2500.000 & All except SAP-B-2150-R & S0 & 0.000 & 0.000 & 0.000 \\
\hline E5 & 3.4 & 2500.000 & All except SAP-B-2150-R & So & 0.000 & 0.000 & 0.000 \\
\hline E6 & 0.1 & 2500.000 & All except SAP-B-2150-R & $\mathrm{S} 1$ & $0.500-1.000$ & $1.165-2.500$ & $11.66-25.00$ \\
\hline E7 & 3.4 & 2500.000 & All except SAP-B-2150-R & $\mathrm{S} 1$ & $0.500-1.000$ & $1.165-2.500$ & $0.342-0.735$ \\
\hline E8 & 0.300 & 500.000 & All except SAP-B-2150-R & $\mathrm{S} 2 / \mathrm{S} 4$ & 22.300 & 11.150 & 37.170 \\
\hline E9 & 0.300 & 500.000 & All except SAP-B-2150-R & $\mathrm{S} 3$ & 3.320 & 1.660 & 5.530 \\
\hline E10 & 0.300 & 150.000 & All except SAP-B-2150-R & $\mathrm{S} 2 / \mathrm{S} 4$ & 22.300 & 3.350 & 11.100 \\
\hline E11 & 1.100 & 150.000 & All except SAP-B-2150-R & $\mathrm{S} 2 / \mathrm{S} 4$ & 22.300 & 3.350 & 3.040 \\
\hline E12 & 1.100 & 300.000 & All except SAP-B-2150-R & $\mathrm{S} 2 / \mathrm{S} 4$ & 22.300 & 6.690 & 6.080 \\
\hline E13 & 1.100 & 400.000 & All except SAP-B-2150-R & $\mathrm{S} 2 / \mathrm{S} 4$ & 22.300 & 8.920 & 8.100 \\
\hline E14 & 1.100 & 440.000 & All except SAP-B-2150-R & $\mathrm{S} 2 / \mathrm{S} 4$ & 22.300 & 9.810 & 8.910 \\
\hline E15 & 1.100 & 500.000 & All except SAP-B-2150-R & $\mathrm{S} 2 / \mathrm{S} 4$ & 22.300 & 11.150 & 10.130 \\
\hline
\end{tabular}

using analytical reagent grade $\mathrm{NaCl}, \mathrm{KCl}$ and $\mathrm{CaCl}_{2}$ solvents. S2 has a high COC $(22.30 \mathrm{mM})$, while S3 has a low COC (3.32 $\mathrm{mM})$. Since the primary ions in the pore solution of cement pastes are $\mathrm{K}^{+}, \mathrm{Na}^{+}$and $\mathrm{Ca}^{2+}$, simulated pore solution $(\mathrm{S} 4, \mathrm{pH}=12.42)$ were prepared using analytical reagent grade $\mathrm{NaCl}, \mathrm{KCl}$ and $\mathrm{Ca}(\mathrm{OH})_{2}$.

\subsection{Experimental design}

Sixteen groups of experiments (Table 3) were designed. All data were averaged by three replicates. Deionized water was used for E0, E1, E4 and E5, while tap water was used for E2, E3, E6 and E7. For E8 - E15, the used liquid was $\mathrm{S} 2 / \mathrm{S} 4$ except for $\mathrm{E} 9$, where $\mathrm{S} 3$ was used. AOC of E8 and E9 varied greatly due to different used solutions (S2/S4 for E8, S3 for E9). AOC of E11 and E15 were quite different due to different volumes of solution $(150 \mathrm{ml}$ for E11, $500 \mathrm{ml}$ for E15). It is important to note that E10 and E11 had the same COC, but the SAP mass differed greatly (0.3 g for E10, $1.1 \mathrm{~g}$ for E11). AOC in solution gradually increased from E11 to E15 due to the increased volume of solution. $\mathrm{N}$ is the proportion between AOC and SAP mass.

In addition, it is worth noting that for group E0 - E3, red SAP B with particle size of 2000-2300 $\mu \mathrm{m}$ (dyed with organic dyes) was used to take photographs. For group E0 and E2 with single red SAP (not suitable for tea bag method owing to too few SAP), the absorption and desorption curves were characterized by weighing the mass of single SAP using analytical balance at scheduled time. However, for E1 and E3 with much SAP, the curves were obtained through classical tea-bag method.

\subsection{Methods for obtaining absorption and de- sorption curves}

The charactering methods for absorption and desorption curves of SAP have been summarized by Schröfl et al. (2017). Among these methods, tea bag method and filtration method are mostly widely applied and the two methods were applied in this study.

\subsubsection{Tea bag method}

Firstly, the tea bags were soaked in a beaker with the prepared liquids in advance. It is necessary to conduct this procedure because it is not easy to eliminate the water absorbed by the tea bags in the process of weighing SAP. Namely, the mass of wet tea bag (not including the water on tea bag surface) needed to be obtained before informal weighing. The beaker was tightly wrapped with plastic foil and the weighing procedures were quite rapid to avoid liquid carbonization. Then the surface water of the tea bags was wiped off with dry cloth and weighed as $m_{1}$. Afterward SAP with a certain mass of $m_{2}$ was put into the tea bags. Then the tea bags containing SAP were suspended and soaked in a beaker containing liquids, and after scheduled time, the tea bags were taken out and weighed as $m_{3}$. In similar manner, the surface water of the tea bags also needed to 
be wiped off before weighing. After weighing, the tea bags were put into the solution to wait for the next test. Because the water absorption rate of SAP in the early stage were faster than that in the later stage, the time interval of weighing was relatively smaller in the early stage, while larger in the later stage. The specific water absorbency can be obtained through the Eq. (1). $\mathrm{A}_{b}$ as a function of time in the absorption and desorption curve of SAP.

$$
\mathrm{A}_{b}=\frac{m_{3}-m_{2}-m_{1}}{m_{1}}
$$

\subsubsection{Filtration method}

The dry SAP $\left(m_{d r y S A P}\right)$ was added to the test liquid in a beaker. The beaker was then tightly covered with the plastic film to avoid carbonization. The filter paper was pre-wetted in the test fluid before filtration. After a distinct time, the mixture was filtered.

The mass increase of SAP is gravimetrically determined as the difference between the initial mass of liquid added $\left(m_{\text {fluid added }}\right)$ and the mass of fluid filtered $\left(m_{\text {fluid filtered }}\right)$ and normalized to the mass of dry SAP. Eq. (2) is used to calculate the absorption capacity. Likewise, $\mathrm{A}_{b}$ as a function of time is the absorption and desorption curve of SAP.

$$
\mathrm{A}_{b}=\frac{m_{\text {fluid added }}-m_{\text {fluid filtered }}}{m_{d r y S A P}}
$$

2 minutes
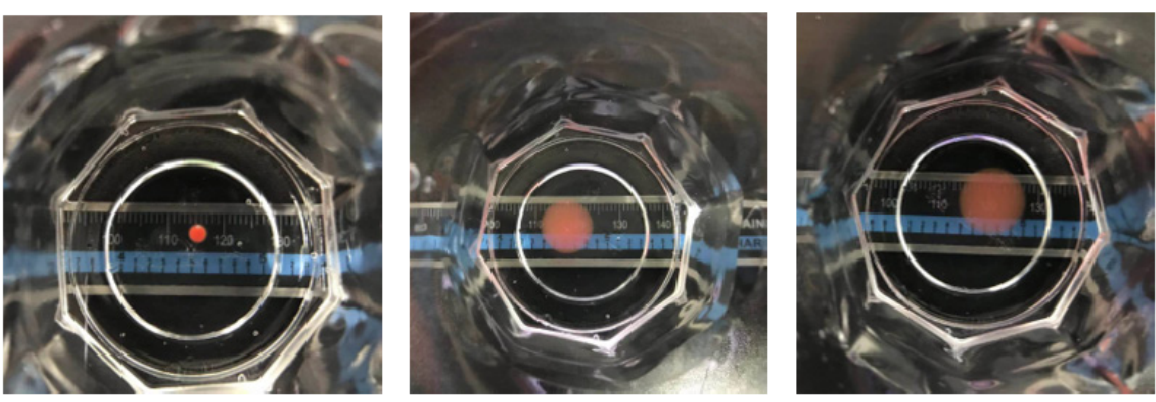

Fig. 2 The effect of SAP mass on the absorption and desorption curves (SAP-B-2150-R) in deionized water.

4 hours

19 hours

E0
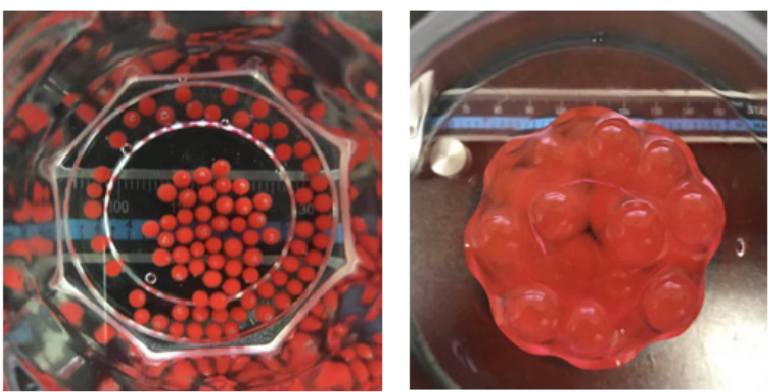

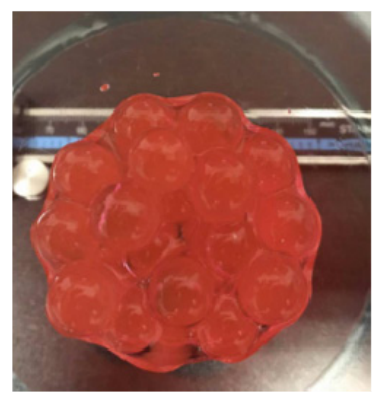

Fig. 3 The volume evolution of SAP in E0 (0.008 g SAP-B-2150-R, top three photos) and E1 (0.68 g SAP-B-2150-R, bottom three photos) in deionized water. 
SAP in deionized water, the single SAP volume with $0.008 \mathrm{~g}$ SAP is nearly same as that with $0.68 \mathrm{~g}$ SAP at 19 hours.

Further, Figs. 6, 7, 8 and 9 show the effect of SAP mass (all except SAP-B-2150-R) on the absorption and desorption curves of SAP in deionized water and tap water. Likewise, in deionized water, SAP mass exert little effect on the absorption and desorption curves of SAP, while SAP mass has a distinct effect on the absorption and desorption behaviors, especially the water retention capacity at 19 hours, whether for different SAP types or different SAP sizes.

As everyone knows, there are small amounts of $\mathrm{Ca}^{2+}$, $\mathrm{Mg}^{2+}$ and $\mathrm{Al}^{3+}$ in tap water but no such ions in deionized water. In deionized water, SAP mass has no effect on

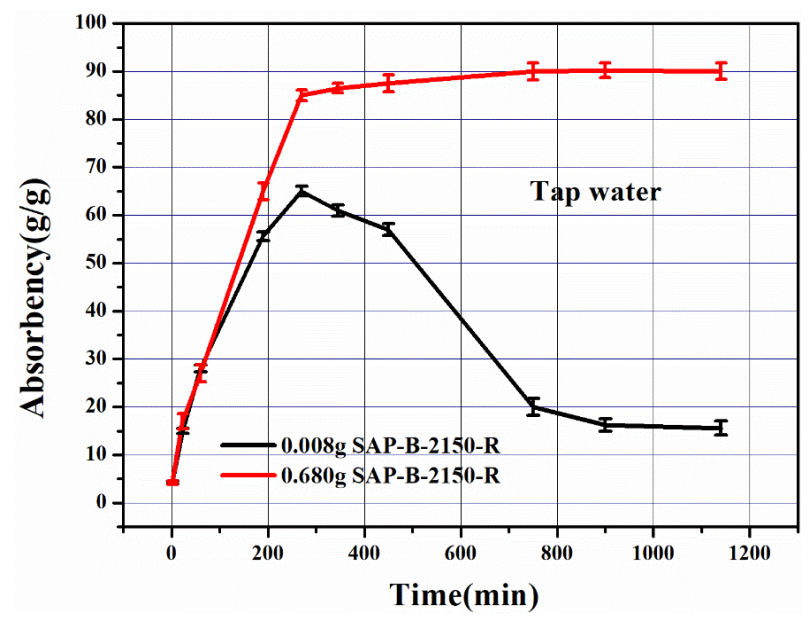

Fig. 4 The effect of SAP mass on the absorption and desorption curves (SAP-B-2150-R) in tap water. the absorption and desorption curve. But the experiment in tap water with a few $\mathrm{Ca}^{2+}, \mathrm{Mg}^{2+}$ and $\mathrm{Al}^{3+}$ showed that the SAP mass has a remarkable influence on the curve, especially the retention capacity of SAP.

\subsection{Absorption and desorption curve in mim- icked pore solution}

Figures 10 and $\mathbf{1 1}$ show the effect of COC in solutions on the absorption and desorption behaviors of SAP. It is clear that the absorption and desorption curves of SAP, especially maximum absorbency or retention capacity, are remarkably influenced by $\mathrm{COC}$ in solution. The proposed explanation by most researchers is the difference of initial COC in solution (Schrofl et al. 2015; Kang et al. 2018).

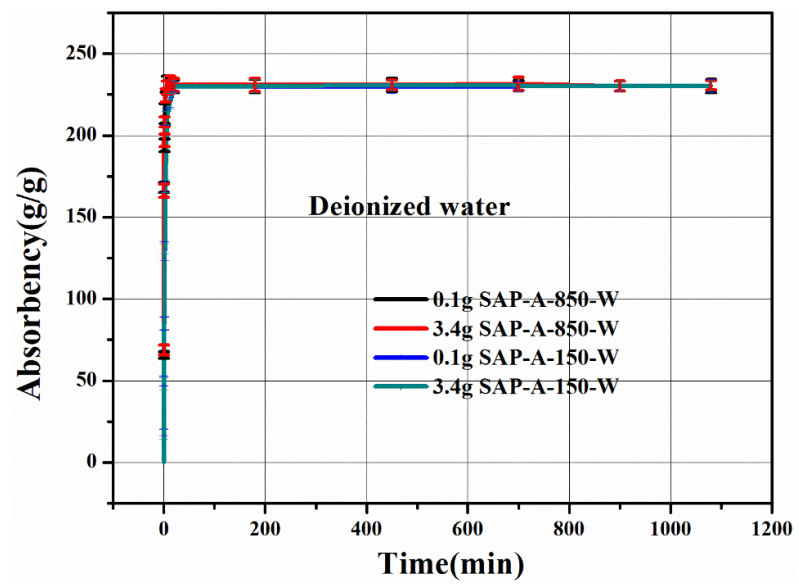

Fig. 6 Effect of SAP (SAP-A-150-W and SAP-A-850-W) on the absorption and desorption curves in deionized water using tea bag method.
2 minutes

E2

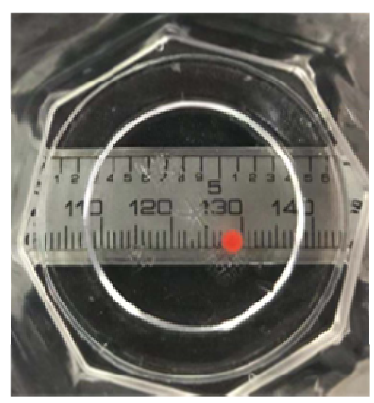

E3

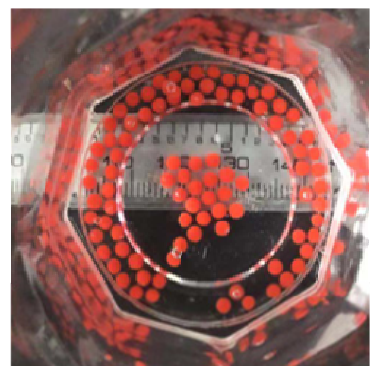

4 hours
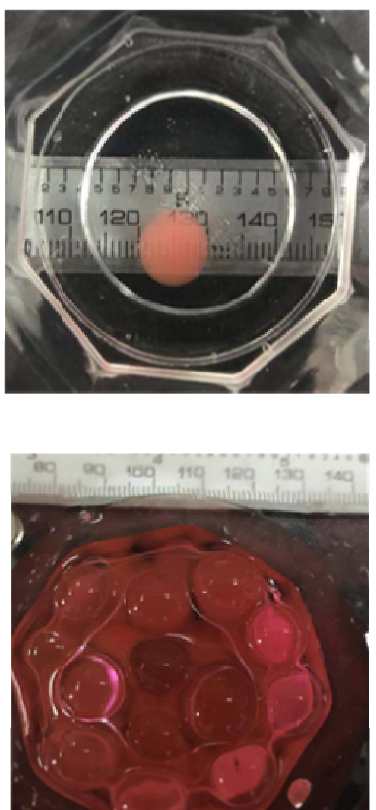

19 hours
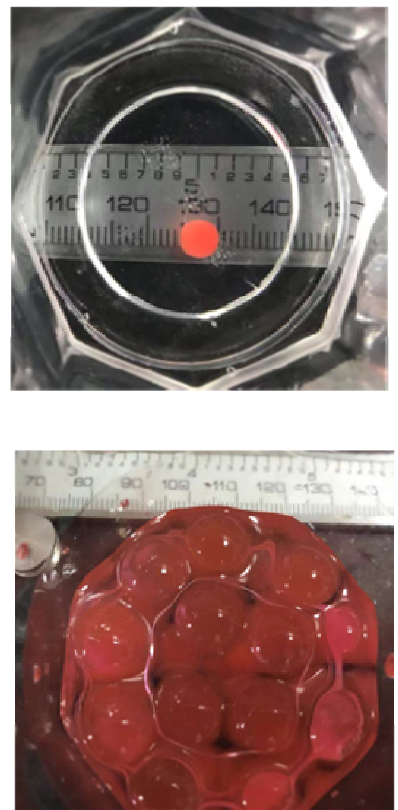

Fig. 5 The volume evolution of SAP in E2 (0.008 g SAP-B-2150-R, top three photos) and E3 (0.68 g SAP-B-2150-R, bottom three photos) in tap water. 
However, even on the premise of same initial COC shown in Table 3, the retention capacity of E11 at $19 \mathrm{~h}$ is significantly different from that of E8, E10 or E15, regardless of SAP types, SAP sizes and tested solutions. The data in Table $\mathbf{4}$ can no longer be explained using the difference of initial COC in solution. How is it explained?

From the results of E8, E10 and E15 with nearly same retention capacity, it seems that AOC or SAP mass has no effects on the final results. But through comparing the retention capacity of E10 and E11, SAP mass have a remarkable effect on the desorption behavior. Likewise, through comparing the retention capacity of E11 and E15, AOC in solution have a dramatic influence on the desorption behavior of SAP as well.

Based on the above analysis, it is evident that if only single factor (AOC or SAP mass) is considered, contradictory conclusions will be reached. In other words, the two factors jointly determine the absorption and desorption behavior of SAP.

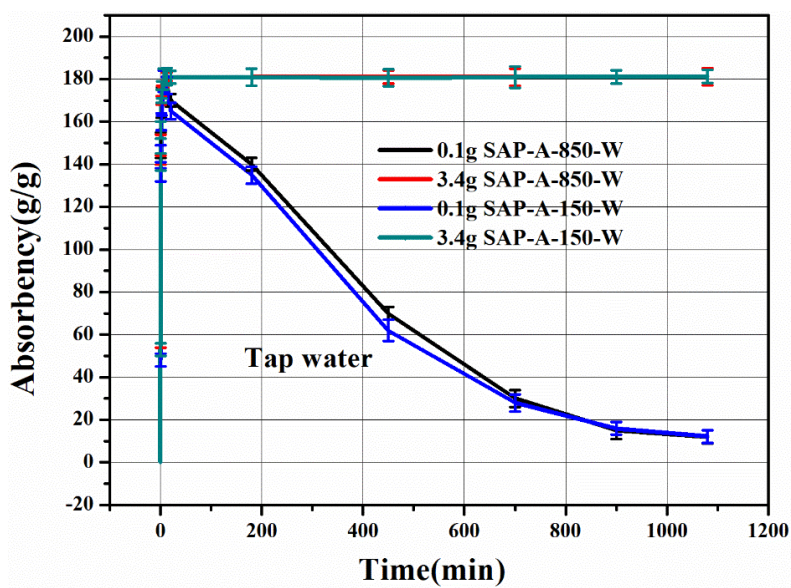

Fig. 7 Effect of SAP mass (SAP-A-150-W and SAP-A-850-W) on the absorption and desorption curves in tap water using tea bag method.

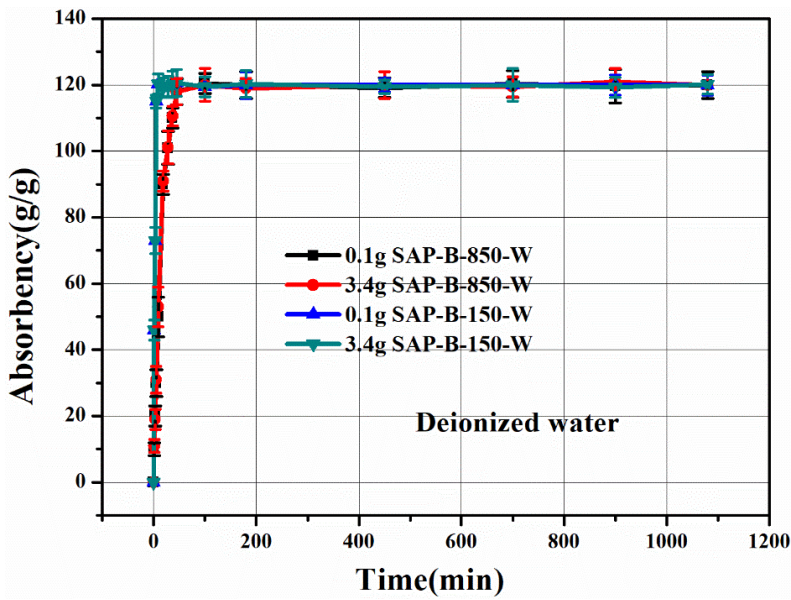

Fig. 8 Effect of SAP mass (SAP-B-150-W and SAP-B-850-W) on the absorption and desorption curves in deionized water using tea bag method.

\subsection{Round-robin test of RILEM TC 260-RSC}

Considering the importance of absorption and desorp-

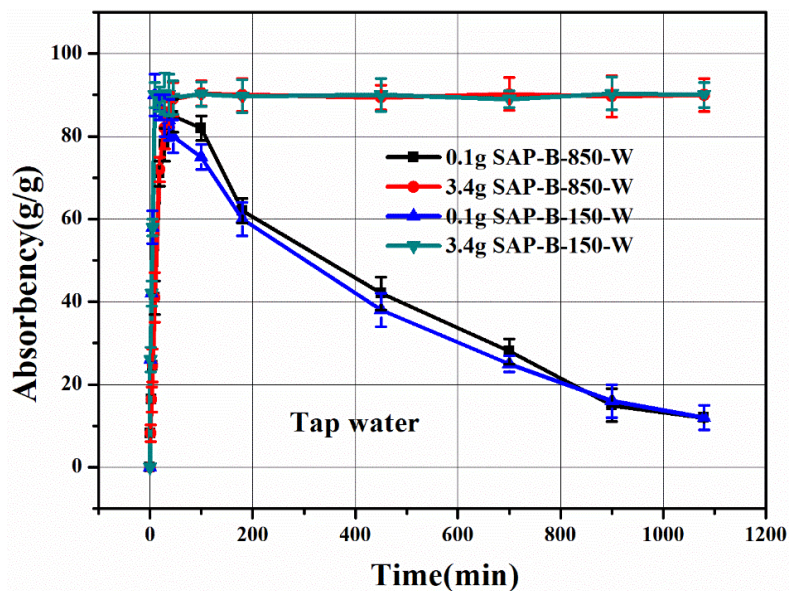

Fig. 9 Effect of SAP mass (SAP-B-150-W and SAP-B-850-W) on the absorption and desorption curves in tap water using tea bag method.

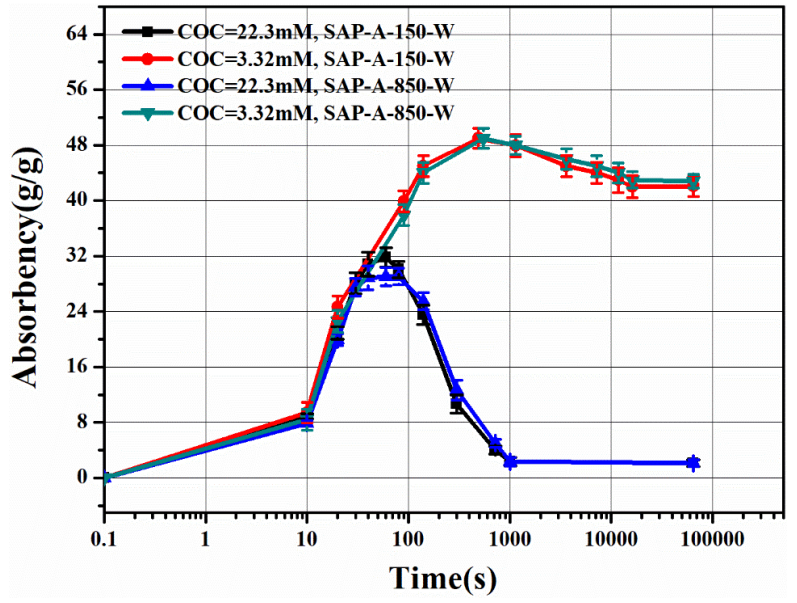

Fig. 10 Effect of $\mathrm{COC}$ in solutions on the absorption and desorption curves of SAP (SAP-A-150-W and SAP-A-850-W) in simulated pore solutions using tea bag method.

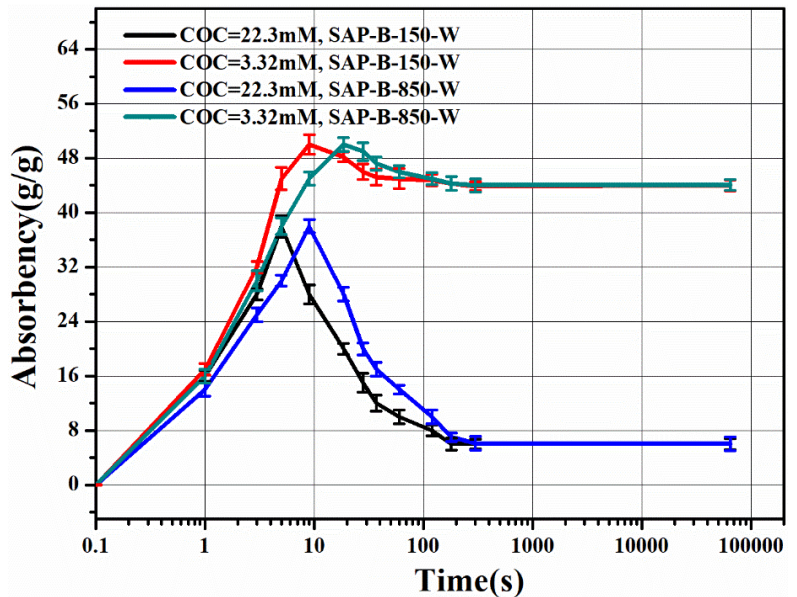

Fig. 11 Effect of COC in solutions on the absorption and desorption curves of SAP (SAP-B-150-W and SAP-B-850-W) in simulated pore solutions using tea bag method. 
Table 4 Effect of AOC on the retention capacity of SAP with different types and sizes at 19 hours in two simulated pore solutions S2/S4. All experiment groups have same initial COC.

\begin{tabular}{ccccc}
\hline Experimental group & SAP-A-150-W $(\mathrm{g} / \mathrm{g})$ & SAP-A-850-W $(\mathrm{g} / \mathrm{g})$ & SAP-B-150-W $(\mathrm{g} / \mathrm{g})$ & SAP-B-850-W $(\mathrm{g} / \mathrm{g})$ \\
\hline $\begin{array}{c}\text { E8 }(0.3 \mathrm{~g} \mathrm{SAP}-500 \mathrm{~mL}, \\
\text { AOC }=11.15 \mathrm{mmol})\end{array}$ & $2.30 / 2.15$ & $2.19 / 2.10$ & $6.02 / 6.10$ & $6.32 / 6.10$ \\
$\begin{array}{l}\text { E10 }(0.3 \mathrm{~g} \text { SAP-150 mL, } \\
\text { AOC }=3.35 \mathrm{mmol})\end{array}$ & $2.10 / 2.20$ & $2.25 / 2.30$ & $6.35 / 6.32$ & $6.22 / 6.23$ \\
$\begin{array}{l}\text { E1 } \quad(1.1 \mathrm{~g} \mathrm{SAP}-150 \mathrm{~mL}, \\
\quad \text { AOC }=3.35 \mathrm{mmol})\end{array}$ & $28.0 / 28.1$ & $28.5 / 28.2$ & $30.2 / 30.5$ & $29.5 / 29.8$ \\
$\begin{array}{l}\text { E15 }(1.1 \mathrm{~g} \mathrm{SAP}-500 \mathrm{~mL}, \\
\text { AOC }=11.15 \mathrm{mmol})\end{array}$ & $2.19 / 2.23$ & $2.32 / 2.13$ & $6.35 / 6.25$ & $6.32 / 6.23$ \\
\hline
\end{tabular}

tion curves and to provide a recommendation for use of SAP in concrete construction, in 2017, RILEM Technical Committee gathered 13 research groups over the world to test sorption properties of SAP, and the absorption and desorption curves measured by the filtration method and the tea bag method were compared (Mechtcherine et al. 2018). It was very surprising that the retention capacity in cement filtrate obtained by the filtration method was quite larger than that obtained by the tea bag method, whereas nearly identical in demineralized water in Fig. 12(b), which is copied from Fig. 7 of the paper by Mechtcherine et al. (2018). To explain this strange result, several possible reasons were pro- vided in Mechtcherine et al. (2018), such as the pore size difference between filter paper and tea bag, the chemical bonds broken in the polymer structure due to the presence of highly alkaline substances or other ions in the test solution and the solution carbonization and evaporation during the experiment. In our opinion, none of these explanations is convincing.

We believe that the difference of the retention capacity in Mechtcherine et al. (2018) does not stem from the adopted methods themselves, but from experimental design. It is important to note that the SAP mass and AOC in solution were not taken into account in Mechtcherine et al. (2018). In their experiments, the

(a)

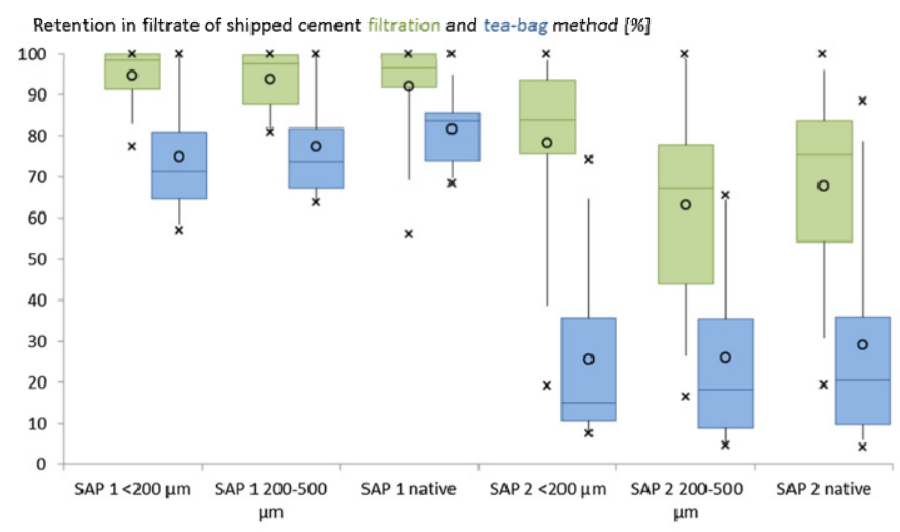

(b)

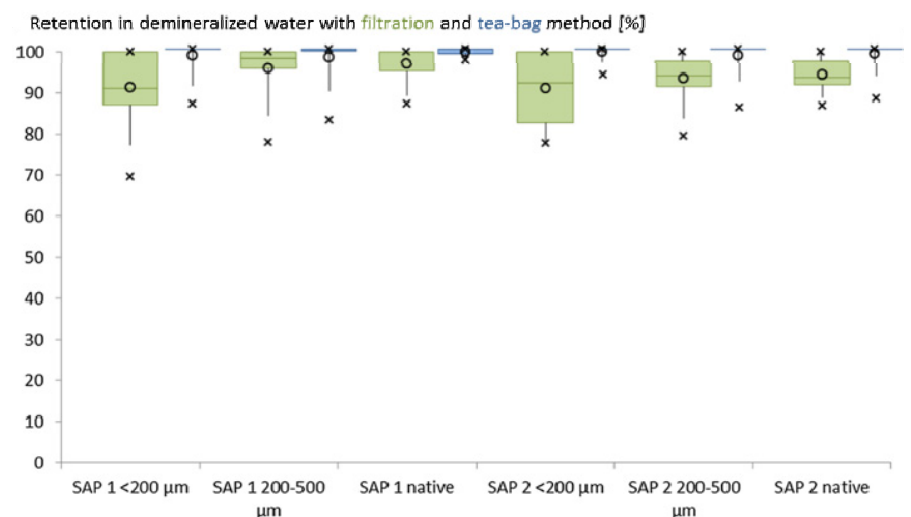

Fig. 12 Retention results (the $24 \mathrm{~h}$ mean absorption capacity related to the maximal recorded mean absorption capacity) obtained by means of the filtration and tea-bag methods as box plots grouped per SAP type and grading: the average values (middle circle ' $\circ$ ' in box), $25-50-75 \%$ quartile intervals (box), 5-95\% intervals (whiskers) and maxima and minima (crosses ' $x$ '). Beneath the respective graphs for the absorption in (a) the shipped cement filtrate and (b) demineralized water, the number of participants is given (n) (Copied from Fig. 7 of Mechtcherine et al. (2018)). 
SAP mass and volume of solution in the tea bag method were $0.2 \mathrm{~g}$ and $200 \mathrm{ml}$, respectively, whereas in the filtration method at least $1 \mathrm{~g}$ and only $100 \mathrm{ml}$.

\subsection{Mechanism influencing the curve from the view of ion exchange equilibrium}

Why do AOC have decisive effect on the curve? We discussed the mechanism from the view of ion exchange equilibrium in this study. Ion exchange is a reversible equivalent reaction between ions and ion exchanger where ion exchanger is composed of the exchangeable ions and framework. According to the requirement of electrical neutrality, the framework must have ions with the opposite sign of exchangeable ions and a fixed equivalent number. Such ions are called fixed ions and fixed ions are also called exchange sites. Figure 13 is a redrawn schematic diagram of cation exchanger from Helfferich (1962).

Ion exchangers are mainly classified into acid cation exchangers and basic anion exchangers. One of the representative acid cation exchangers is acrylic cation exchanger, and its ion exchange functional group is - $\mathrm{COO}^{-}$ The main component of SAP is acrylic acid, containing lots of $-\mathrm{COO}^{-}$. Therefore, we can regard SAP as a cation exchanger.

According to above analysis, as an ion exchanger, SAP also follows the general theory of ion exchangers. For weak acid cation exchanger, the selectivity to $\mathrm{Ca}^{2+}$ is generally greater than that of monovalent ions, such as $\mathrm{Na}^{+}$and $\mathrm{K}^{+}$(Helfferich 1962). This is the reason why SAP selectively absorbs $\mathrm{Ca}^{2+}$ and release $\mathrm{Na}^{+}$or $\mathrm{K}^{+}$. In a solution containing $\mathrm{Ca}^{2+}, \mathrm{Na}^{+}$and $\mathrm{K}^{+}$, the ion exchange between SAP and $\mathrm{Ca}^{2+}, \mathrm{Na}^{+}$and $\mathrm{K}^{+}$will reach an equilibrium. The ion exchange equilibrium can be expressed using Eq. (3),

$$
\begin{aligned}
& \mathrm{Ca}^{2+}+2\left(\mathrm{R}-\mathrm{COO}^{-}\right) \mathrm{B}^{+} \rightleftharpoons 2 \mathrm{~B}^{+}+\left(\mathrm{R}-\mathrm{COO}^{-}\right)_{2} \mathrm{Ca}^{2+} \\
& \text { Solution Resinphase Solution Resinphase } \\
& \text { Phase } \\
& \text { Phase }
\end{aligned}
$$

where $\mathrm{R}_{-} \mathrm{COO}^{-}$is fixed ions and $\mathrm{B}^{+}$is $\mathrm{Na}^{+}$or $\mathrm{K}^{+}$. According to the law of mass action, the reaction equilibrium equation of Eq. (3) can be described by Eq. (4).

$$
K=\frac{\left(a_{\mathrm{B}}\right)^{2} \cdot\left(a_{\mathrm{R}_{2} \mathrm{Ca}}\right)}{\left(a_{\mathrm{Ca}}\right)\left(a_{\mathrm{RB}}\right)^{2}}
$$

where $K$ is equilibrium constant, and $a_{\mathrm{B}}$ and $a_{\mathrm{Ca}}$ are the activities of ions $\mathrm{B}$ and $\mathrm{Ca}^{2+}$ in solution respectively, and $a_{\mathrm{RB}}$ and $a_{\mathrm{R}_{2} \mathrm{Ca}}$ represent the corresponding activities of ions $\mathrm{B}$ and $\mathrm{Ca}^{2+}$ in SAP respectively. Generally speaking, $a_{\mathrm{B}}$ and $a_{\mathrm{Ca}}$ can be substituted by corresponding molar concentration. The $a_{\mathrm{RB}}$ and $a_{\mathrm{R}_{2} \mathrm{Ca}}$ is determined by the SAP type. According to Eq. (4), it is not difficult to find that $a_{\mathrm{R}_{2} \mathrm{Ca}}$, which determines the absorption and desorption curve of SAP, is affected by $a_{\mathrm{B}}, a_{\mathrm{Ca}}$ and $a_{\mathrm{RB}}$.

From the view of ion exchange equilibrium, we can explain the effect of AOC on the absorption and desorption curve of SAP in this study. Due to the interaction of ion exchange adsorption (Kang et al. 2018; Lee et al. 2018; Helfferich 1962), SAP as an ion exchanger will continuously absorb $\mathrm{Ca}^{2+}$ and release $\mathrm{Na}^{+}$in the liquid containing $\mathrm{Ca}^{2+}, \mathrm{Na}^{+}$and $\mathrm{K}^{+}$. In other words, $\mathrm{Ca}^{2+}$ is cumulative inside SAP and decreasing in solution over time. If the ratio between AOC and tested SAP mass in liquid is very small, AOC in solution will dramatically reduce to a low level, resulting in the quite low $\mathrm{COC}$ in solution. Based on the above introduction, the low COC means the low $a_{\mathrm{Ca}}$, resulting in low $a_{\mathrm{R}_{2} \mathrm{Ca}}$, consequently inhibiting the release of water. This is also the essential reason why the retention capacity obtained by the filtration method is a lot larger than that obtained by the tea bag method in round-robin test of RILEM TC 260-RSC.

Furthermore, as $a_{\mathrm{B}}$ and $a_{\mathrm{RB}}$ are determined by the alkalinity and chemical composition of SAP respectively, we can deduce that the alkalinity of solution and chemical composition of SAP, in addition to AOC and $\mathrm{COC}$, have also decisive effects on the absorption and desorption curve. And this deduction has been confirmed by some experimental studies (Schrofl et al. 2012; Kang et al. 2018; Lee et al. 2018). Lee et al. (2018) found the alkalinity and COC in pore solution had critical effect on the absorption and desorption curve of SAP. Likewise, Kang et al. (2018) have concluded that higher $\mathrm{Na}^{+}, \mathrm{K}^{+}$concentrations (higher alka-

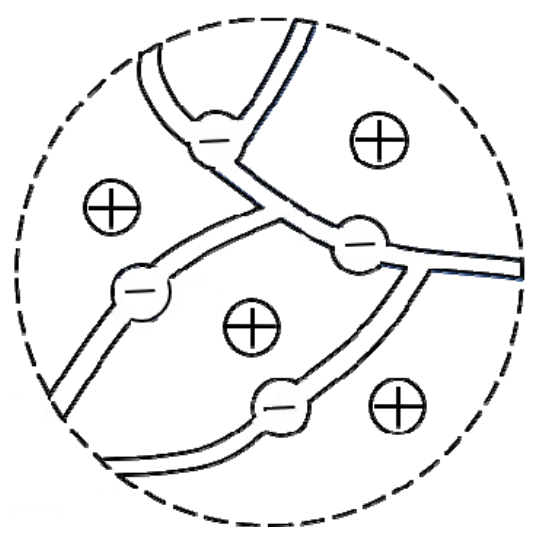

$\oplus$ Exchangeable positive ion

fs A skeleton part with a fixed ion

Fig. 13 Redrawn schematic map of cation exchanger, from the work of Helfferich (1962). 
linity) in pore solution improved the water retention capacity of SAP. From the view of ion exchange equilibrium, the results can be well explained. Higher alkalinity means higher $a_{\mathrm{B}}$, resulting in lower $a_{\mathrm{R}_{2} \mathrm{Ca}}$ and therefore higher retention capacity, based on the Eq. (4). Schrofl et al. (2012) found that SAP with higher level of anionic group density (difference of SAP type) had the lower retention capacity in solution containing $\mathrm{Ca}^{2+}$. Likewise, from the view of ion exchange equilibrium, the results can also be explained well. Higher level of anionic group density means higher $a_{\mathrm{RB}}$, resulting in higher $a_{\mathrm{R}_{2} \mathrm{Ca}}$ and therefore lower retention capacity, based on the Eq. (4).

\subsection{Recommendation}

It is well known that in real cement paste, AOC is always enough due to continuous hydration. In order to reflect this fact, there are supposed to be enough AOC when measuring the curve in liquid. But how much is the appropriate ratio between $\mathrm{AOC}$ and SAP mass $\left(\mathrm{N}=\mathrm{AOC} / \mathrm{M}_{\mathrm{SAP}}\right)$ ?

Figure 14 shows the water retention capacity of SAP at $19 \mathrm{~h}$ in simulated pore solution $\mathrm{S} 4$ as a function of $\mathrm{N}$ (two SAP types and two particle sizes). It is clear that with the increase of $\mathrm{N}$, the water retention capacity of all SAPs first decreases and then keep constant, regardless of SAP types and particle sizes. Besides, whether for SAP A or for SAP B, the particle size has no effect on the proper $\mathrm{N}$. However, the proper $\mathrm{N}(9 \mathrm{mmol} / \mathrm{g})$ for SAP A is bigger than that $(8.1 \mathrm{mmol} / \mathrm{g})$ for SAP B. In other words, different SAP types have different proper $\mathrm{N}$, which may be attributed to different crosslinking degree of two SAPs from different companies.

Further, based on the analysis in Section 3.4, AOC, COC, SAP type, alkalinity, etc. all have decisive effect on the curve. In other words, although $\mathrm{N}\left(\mathrm{AOC} / \mathrm{M}_{\mathrm{SAP}}\right)$ is identical or close, the absorption and desorption curves of SAP with different SAP type or different COC or different alkalinity may differ markedly. For example, although N of E9 with low COC (S3) is close to that of E12 with high COC (S4), the retention capacity (40-44

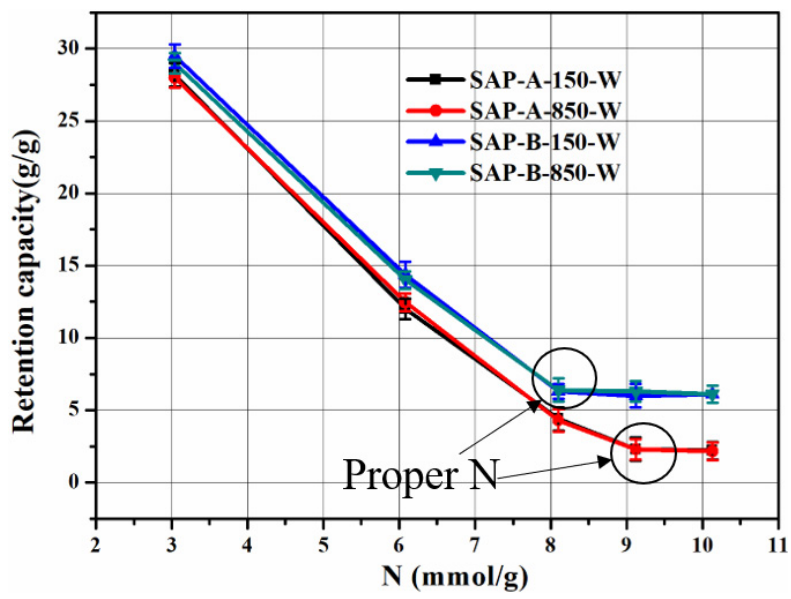

Fig. 14 The retention capacity of SAP at $19 \mathrm{~h}$ as a function of $\mathrm{N}$ for different SAP type and SAP sizes in S4. $\mathrm{g} / \mathrm{g})$ of SAP in E9 is quite larger than that $(12-15 \mathrm{~g} / \mathrm{g})$ in E12. Furthermore, owing to these differences, the appropriate $\mathrm{N}$ may be quite different. Thus, before measuring the absorption and desorption curve of SAP by the tea bag method or the filtration method, it is suggested that $\mathrm{N}$ as the function of the retention capacity need to be determined in advance.

\section{Conclusions}

The effect of amount of $\mathrm{Ca}^{2+}$ on the measured absorption and desorption curve of SAP, and the mechanism influencing the curve are studied in this paper. The conclusions are summarized as follows:

(1) The proportion between amount of $\mathrm{Ca}^{2+}$ and SAP mass has a remarkable influence on the absorption and desorption curve of SAP, whether for different SAP types, for different particle sizes or for different solutions.

(2) The difference of the retention capacity between the tea bag method and the filtration method in Round-robin test of RILEM Technical Committee 260-RSC (Mechtcherine et al. 2018) comes from the proportion difference between amount of $\mathrm{Ca}^{2+}$ and SAP mass.

(3) From the view of ion exchange equilibrium, the reason why amount of $\mathrm{Ca}^{2+}$, concentration of $\mathrm{Ca}^{2+}$, SAP type, alkalinity, etc. have decisive effect on the absorption and desorption curve can be explained.

(4) In order to accurately measure the absorption and desorption curve of SAP with definite SAP type, size and solution, it is suggested that researchers should determine the relation between the ratio of amount of $\mathrm{Ca}^{2+}$ to SAP mass and the retention capacity in advance before formal measurement, so as to select the appropriate SAP mass and the amount of $\mathrm{Ca}^{2+}$ in formal tests. For example, in the field of SAP internal curing, different SAP types might have the different proper $\mathrm{N}$ (the ratio between amount of $\mathrm{Ca}^{2+}$ and SAP mass).

\section{References}

Bentz, D. P. and Jensen, O. M., (2004). "Mitigation strategies for autogenous shrinkage cracking." Cement and Concrete Composites, 26(6), 677-685.

Bowman, D. C., Evans, R. Y. and Paul, J. L., (1990). "Fertilizer salts reduce hydration of polyacrylamide gels and affect physical properties of gel-amended container media." Journal of the American Society for Horticultural Science, 115(3), 382-386.

Davis, C. R., Kelly, S. L. and Erk, K. A., (2018). "Comparing laser diffraction and optical microscopy for characterizing superabsorbent polymer particle morphology, size and swelling capacity." Journal of Applied Polymer Science, 135(14), Article ID 46055.

Esteves, L. P., (2015). "Recommended method for measurement of absorbency of superabsorbent polymers in cement-based materials." Materials and Structures, 
48(8), 2397-2401.

Helfferich, F. G., (1962). "Ion exchange." North Chelmsford, Massachusetts, USA: Courier Corporation.

Jar, P. B. and Wu, Y. S., (1997). "Effect of counter-ions on swelling and shrinkage of polyacrylamide-based ionic gels." Polymer, 38(10), 2557-2560.

Jensen, O. M. and Hansen, P. F., (2001). "Water-entrained cement-based materials: I. Principles and theoretical background." Cement and Concrete Research, 31(4), 647-654.

Jensen, O. M. and Hansen, P. F., (2002). "Water-entrained cement-based materials, Part II: Experimental observations." Cement and Concrete Research, 32(6), 973-978.

Jensen, O. M. and Lura, P., (2006). "Techniques and materials for internal water curing of concrete." Materials and Structures, 39(9), 817-825.

Justs, J., Wyrzykowski, M., Bajare, D. and Lura, P., (2015). "Internal curing by superabsorbent polymers in ultra-high performance concrete." Cement and Concrete Research, 76, 82-90.

Kang, S. H., Gyephel, T., Hong, S. G. and Moon, J., (2015). "Effect of water-entraining admixtures on the hydro-mechanical properties of ultra-high performance concrete." In: Proc. 14th International Congress on the Chemistry of Cement, Beijing 10-15 October 2015.

Kang, S. H., Hong, S. G. and Moon, J., (2017). "Absorption kinetics of superabsorbent polymers (SAP) in various cement-based solutions." Cement and Concrete Research, 97, 73-83.

Kang, S. H., Hong, S. G. and Moon, J., (2018). "Importance of monovalent ions on water retention capacity of superabsorbent polymer in cement-based solutions." Cement and Concrete Composites, 88, 64-72.

Laustsen, S., Hasholt, M. T. and Jensen, O. M., (2015). "Void structure of concrete with superabsorbent polymers and its relation to frost resistance of concrete." Materials and Structures, 48(1), 357-368.

Lee, H. X. D., Wong, H. S. and Buenfeld, N. R., (2010). "Potential of superabsorbent polymer for self-sealing cracks in concrete." Advances in Applied Ceramics, 109(5), 296-302.

Lee, H. X. D., Wong, H. S. and Buenfeld, N. R., (2016). "Self-sealing of cracks in concrete using superabsorbent polymers." Cement and Concrete Research, 79, 194-208.

Lee, H. X. D., Wong, H. S. and Buenfeld, N. R., (2018). "Effect of alkalinity and calcium concentration of pore solution on the swelling and ionic exchange of superabsorbent polymers in cement paste." Cement and Concrete Composites, 88, 150-164.

Lee, W. F. and Wu, R. J., (1996). "Superabsorbent polymeric materials, Part I: Swelling behaviors of crosslinked poly (sodium acrylate-co-ohydroxyethyl methacrylate) in aqueous salt solution." Journal of Applied Polymer Science, 62(7), 1099-1114.

Mechtcherine, V., Snoeck, D., Schröfl, C., De Belie, N.,
Klemm, A. J., Ichimiya, K., Moon, J., Wyrzykowski, M., Lura, P., Toropovs, N., Assmann, A., Igarashi, S., De La Varga, I., Almeida, F. C. R., Erk, K., Ribeiro, A. B., Custódio, J., Reinhardt, H. W. and Falikman, V., (2018). "Testing superabsorbent polymer (SAP) sorption properties prior to implementation in concrete: Results of a RILEM round-robin test." Materials and Structures, 51(1), 1-16.

Mönnig, S. and Lura, P., (2007). "Superabsorbent polymers - An additive to increase the freeze-thaw resistance of high strength concrete." In: Advances in Construction Materials. Berlin and Heidelberg: Springer, 351-388.

Schröfl, C., Mechtcherine, V. and Gorges, M., (2012). "Relation between the molecular structure and the efficiency of superabsorbent polymers (SAP) as concrete admixture to mitigate autogenous shrinkage." Cement and Concrete Research, 42(6), 865-873.

Schroefl, C., Mechtcherine, V., Vontobel, P., Hovind, J. and Lehmann, E., (2015). "Sorption kinetics of superabsorbent polymers (SAPs) in fresh Portland cement-based pastes visualized and quantified by neutron radiography and correlated to the progress of cement hydration." Cement and Concrete Research, $75,1-13$

Schröfl, C., Snoeck, D. and Mechtcherine, V., (2017). "A review of characterisation methods for superabsorbent polymer (SAP) samples to be used in cement-based construction materials (Report of the RILEM TC 260-RSC)." Materials and Structures, 50(4), 1-19.

Siriwatwechakul, W., Siramanont, J. and Vichit-Vadakan, W., (2012). "Behavior of superabsorbent polymers in calcium-and sodium-rich solutions." Journal of Materials in Civil Engineering, 24(8), 976-980.

Snoeck, D., Jensen, O. M. and De Belie, N., (2015). "The influence of superabsorbent polymers on the autogenous shrinkage properties of cement pastes with supplementary cementitious materials." Cement and Concrete Research, 74, 59-67.

Snoeck, D., Pel, L. and De Belie, N., (2017). "The water kinetics of superabsorbent polymers during cement hydration and internal curing visualized and studied by NMR." Scientific Reports, 7(1), 1-14.

Snoeck, D., Schaubroeck, D., Dubruel, P. and De Belie, N., (2014). "Effect of high amounts of superabsorbent polymers and additional water on the workability, microstructure and strength of mortars with a water-to-cement ratio of 0.50." Construction and Building Materials, 72, 148-157.

Snoeck, D., Steuperaert, S., Van Tittelboom, K., Dubruel, P. and De Belie, N., (2012). "Visualization of water penetration in cementitious materials with superabsorbent polymers by means of neutron radiography." Cement and Concrete Research, 42(8), 1113-1121.

Tsuji, M., Okuyama, A., Enoki, K. and Suksawang, S., (1998). "Development of new concrete admixture preventing from leakage of water through cracks." 
JCA Proceedings of Cement \& Concrete (Japan Cement Association), 52, 418-423. (in Japanese)

Tsuji, M., Shitama, K. and Isobe, D., (1999). "Basic studies on simplified curing technique, and prevention of initial cracking and leakage of water through cracks of concrete by applying superabsorbent polymers as new concrete admixture." Zairyo, 48(11), 1308-1315. (in Japanese)

Yang, J., Wang, F., Liu, Z., Liu, Y. and Hu, S., (2019). "Early-state water migration characteristics of superabsorbent polymers in cement pastes." Cement and Concrete Research, 118, 25-37.

Yarimkaya, S. and Basan, H., (2007). "Synthesis and swelling behavior of acrylate-based hydrogels." Journal of Macromolecular Science, Part A: Pure and Applied Chemistry, 44(7), 699-706.

Zhao, S., Jensen, O. M. and Hasholt, M. T., (2020). "Measuring absorption of superabsorbent polymers in cementitious environments." Materials and Structures, 53(1), 1-16.

Zhu, Q., Barney, C. W. and Erk, K. A., (2015). "Effect of ionic crosslinking on the swelling and mechanical response of model superabsorbent polymer hydrogels for internally cured concrete." Materials and Structures, 48(7), 2261-2276. 